\title{
Features of formation and reduction of sulfur dioxide emissions when burning brown coal in boilers with liquid slag removal
}

\author{
Vladimir Elsukov ${ }^{1, *}$, and Svetlana Latushkina ${ }^{1}$ \\ ${ }^{1}$ Bratsk State University, 40 Makarenko st., Bratsk, Russia
}

\begin{abstract}
The paper considers the influence of technological factors (design of the boiler-unit, load, air excess, the number of working dust collecting systems) on the formation and reduction of sulfur dioxide emissions in boilers with liquid slag removal. Understanding of this influence can be used both at many operating heat and power sources, and in the development of new combustion technologies. The long-term experience of burning brown coals of the Kansk-Achinsk basin (KAC) at CHPP-6 in Bratsk in boilers of the BKZ-320-140 PT type is studied and analyzed. The analysis uses the results of various thermodynamic and industrial studies of the sulfur dioxide formation during the combustion of KAC, including those carried out by the authors. They identified the temperature and structural zones of the boiler unit, where the resulting reaction of the sulfur dioxide transition to calcium sulfate occurs. It was found that such a zone is the upper part of the cooling chamber, where the indicated transition occurs at temperatures of $1500 \div 1400 \mathrm{~K}$. It was found that $\mathrm{SO}_{2}$ emissions rise with an increase in the boiler load and air excess. They also depend on the number of dust systems and their combination (determining the turbulization of combustion processes). A technological mechanism for the sulfur dioxide transition to calcium sulfate for the operation of boilers with liquid slag removal is proposed. Regime and constructive measures are proposed to reduce emissions of sulfur dioxide.
\end{abstract}

Keywords. Boilers with liquid slag removal, calcium sulfate, sulfur dioxide, excess air, boiler load, dustforest systems, pollutant emissions, thermodynamic modeling of combustion processes

\section{Introduction}

The identification and clarification of factors increasing the efficiency of boilers with liquid slag removal can be in demand both at many operating TPPs and in the development of new combustion technologies. In this paper the authors analyze the long-term experience of burning Kansk-Achinsk coals (KAC) at CHPP-6 in Bratsk in boilers of the BKZ-320-140 PT type. The above experience includes successful upgrades of combustion technologies of the KAU IrshaBorodinskoye field, as a result of which emissions of nitrogen oxides (NOx) were significantly reduced [1], as well as experimental studies, during which the concentrations of $\mathrm{NOx}$, sulfur dioxide $\left(\mathrm{SO}_{2}\right)$, benzo [a] pyrene $(\mathrm{BaP})$ were measured at various points of the boiler, and other technical and economic parameters $[1,2]$.

All values of various parameters presented in these reports and publications [1,2] coincide with the exception of $\mathrm{SO}_{2}$ concentrations. In the paper [2], the concentration of $\mathrm{SO}_{2}$ in the effluent gases during the combustion of KAC of the Irsha-Borodinskoye field is $\approx$ $100-150 \mathrm{mg} / \mathrm{m}^{3}$, and in publication [1] $\approx 330 \mathrm{mg} / \mathrm{m}^{3}$. The differences in the presented $\mathrm{SO}_{2}$ values are explained by the doubts of the authors [1] in the reliability of the $\mathrm{SO}_{2}$ determination method. Currently, there are repeated measurements of $\mathrm{SO}_{2}$ carried out at the station by various organizations, in which, when burning Irsha-Borodinsky coal, $\mathrm{SO}_{2}$ emissions were always recorded less than $200 \mathrm{mg} / \mathrm{m}^{3}$. Taking these measurements into account, this study gives the $\mathrm{SO}_{2}$ values from the above work [2] as more representative in comparison with [1].

When analyzing the experimental data, the authors of this paper employed the results of the thermodynamic calculations of the KAC combustion carried out at the Siberian Power Engineering Institute (SEI, now ISEM) $[3,4]$, including by the author [5].

In a number of kinetic studies [6] it was found that with a lack of air, sulfur-containing combustion products of fuel oil consist of $\mathrm{H}_{2} \mathrm{~S}, \mathrm{~S}, \mathrm{SH}, \mathrm{SO}, \mathrm{SO}_{2}$, and the concentration of sulfur oxides tends to zero. Under stoichiometric conditions, sulfur is mainly represented in the form of $\mathrm{SO}$ and $\mathrm{SO}_{2}$, and traces of sulfuric anhydride

\footnotetext{
* Corresponding author: $\underline{\text { elswk@mail.ru }}$
} 
appear in the system. At $\alpha>1$, the highest sulfur oxides $\mathrm{SO}_{2}$ and $\mathrm{SO}_{3}$ prevail. Both domestic [7,8] and foreign researchers believe that the oxidation of sulfur dioxide to sulfuric anhydride is $0.2-2.5 \%$ for boiler units.

When burning solid fuel containing alkali metal oxides, reactions can occur such as:

$$
\mathrm{CaO}_{(\mathrm{c})}+\mathrm{SO}_{2}+0,5 \mathrm{O}_{2}=\mathrm{CaSO}_{4(\mathrm{c})}-500 \kappa \mathrm{J} / \mathrm{\kappa mol}(1)
$$

Note that for the KAC Irsha-Borodinsky deposit, the molar ratio of calcium to sulfur $(\mathrm{Ca} / \mathrm{S})$ is approximately equal to three.

Until recently, this reaction has practically not been studied in relation to the combustion of KAC. This can be explained by the fact that during the combustion of $\mathrm{KAC}$ in traditional furnaces with the corresponding operating parameters, the formation of condensed gypsum occurred only to an insignificant extent, the equilibrium of reaction (1) was shifted to the left. It is believed that the gypsum formation reaction takes place mainly in the boiler flue pipes at low temperatures. This provision is incorporated into the methodology for determining emissions of sulfur compounds from boilers $[9,10]$.

However, in connection with the recent development of technologies for low-temperature combustion of solid fuel, the above approach can lead to large inaccuracies or errors. Therefore, it becomes necessary to provide accurate information on the conditions of reaction (1) as applied to the combustion of KAC. When conducting thermodynamic studies of the KAC combustion $[3,4,5]$, the authors found that in the state of thermodynamic equilibrium, all sulfur in the fuel is converted to $\mathrm{CaSO} 4$ at $\mathrm{T}<1400 \mathrm{~K}$ and the air excess coefficient $\alpha=1.2$; the transition begins at $\mathrm{T} \approx 1500 \mathrm{~K}$. It can be assumed that, upon combustion of other fuels (with different $\mathrm{Ca} / \mathrm{S}$ molar ratios), the transition temperatures will change.

The results obtained are important because such combustion conditions are suitable not only for fluidized bed boilers, but also for some solid fuel flaring technologies, which will be discussed below. It follows that, in principle, it is possible to achieve a significant reduction in sulfur emissions from boilers using appropriate combustion technologies without the use of expensive de-sulfurization plants.

The parameters of the transition of gaseous sulphide anhydride to gypsum established during thermodynamic studies require experimental confirmation. It is also important to understand what the thermodynamic limitations of this transition depend on in order to obtain the possibility of increasing the temperature of gypsum formation and expanding the range of corresponding combustion technologies.

\section{Combustion implemented in boilers}

technologies

The boiler is equipped with four individual dust systems with an industrial bunker. Drying and transportation of dust in the pulverization system is carried out by a mixture of "hot" and "cold" flue gases. The boilers are equipped with 16 systems for the supply and combustion of high density dust under vacuum (HDDV), including dust pipes, steam ejectors and burners. Moreover, for each of the 8 primary burners (see Fig. 1), two dust lines are installed. The above papers $[1,2]$ consider experiments carried out on various boilers (boiler units) of the station, including at the boiler units No. 5 and 7. B.u. No. 5 was equipped with two closed $(B, C)$ and two open dust collecting systems (CS), and at b.u. No. 7 (and other boilers) all dust collecting systems were closed (Fig. 2). For our further analysis it is important to note that the discharges of the drying agent from closed dust systems are brought into the upper part of the combustion chamber above the primary burners, and from open dust systems A and D (b.u.No. 5) - into the gas duct in front of the multicyclone collector.

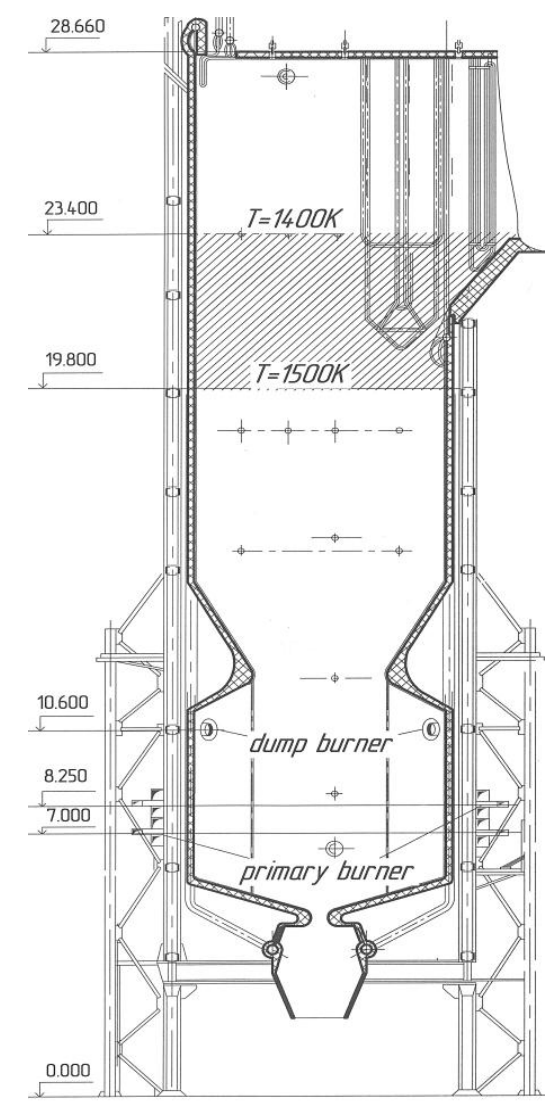

Fig. 1. Boiler furnace BKZ-320-140PT

Furnace b.u. (Fig. 1) is divided by protrusions of the front and rear screens into combustion and cooling chambers with a length of $\approx 6.3$ and $19 \mathrm{~m}$, respectively. The cooling chamber has a rectangular section, and the combustion chamber has a section of two communicating octahedrons (Fig. 2.). On the side faces of these octahedrons, two-tier burners are installed, the axes of which are directed tangentially to imaginary circles with a diameter of $0.98 \mathrm{~m}$. Thus, the combustion chamber includes two pre-furnaces, in which "cyclonic" vertical torches are formed.

The concentrations of pollutants were determined according to the methods of the CAB ARRI promgas ( the Cental Asian Branch of All-Russian Research Institute promgas). 


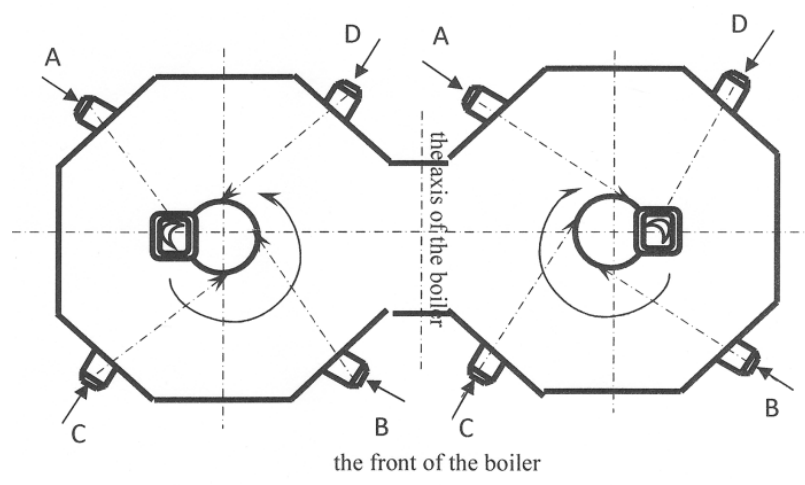

Fig. 2. Diagram of the combustion chamber in plan (A-D supply of waste gases from the corresponding dust systems)

Since 2005, the plant began to burn KAC of small deposits (Kansky, Irbeysky and others). The use of KAC from these fields has led to a sharp increase in emissions of the main gaseous pollutants: $\mathrm{NOx}$ and $\mathrm{SO}_{2}$. The aim of this paper is to analyze the environmental characteristics of the combustion processes of KAU and identify technical solutions to reduce emissions of all major pollutants, including $\mathrm{SO}_{2}$.

\section{Test results}

To identify new patterns in the formation of pollutants, let us consider the results of tests of the b.u. No.5 and 7, stated in the above conclusion, taking into account the aerodynamics correspond to the numbers of the experiments. Numbers consisting of one figure refer to b.u. No.5, and the numbers of two figures, the first of which is $7,-$ to b.u. No.7.

11 experiments were carried out at the b.u. No.5. During experiments the working dust collecting systems were changed, and $\alpha_{\mathrm{s}}$ (steam superheater) and Gs (steam consumption for ejectors) were varied, all of them are shown in Fig. 3. 18 experiments were carried out at the b.u. No.7. 4 of them are shown in Fig.3 to give an opportunity to compare them with b.u. No.5.

$\mathrm{SO}_{2}$ concentrations were measured at the output of the furnace. All values have been refined by the authors of the presented work for standard conditions determined with an excess of air in the exhaust gases $\left(\alpha_{\text {exh }}\right)$ 1.4.

Figure 1 shows the area (shaded) where the flue gases have the above temperatures. The lines of gas temperatures marked in Fig. 1 are constructed according to the literature data [1] and correspond to the boiler load $\mathrm{D}=300 \mathrm{t} / \mathrm{h}$ and $\alpha_{\mathrm{s}}=1.3$. Let us note some provisions of the boiler unit operation that are important for further analysis. When gaseous working bodies (water vapor, air, etc.) are introduced into the combustion chamber, the temperature in the combustion chamber decreases, and at the output of the cooling chamber it rises. This result can be explained by a decrease in the residence time of the combustion products in the cooling chamber and was recorded during tests [1].

Figure 3 shows the results of the $\mathrm{SO}_{2}$ content measurements in flue gases depending on the load (D), excess air behind the superheater $\left(\alpha_{s}\right)$ and the combination of working dust cjllecting systems. The analysis of the obtained characteristics indicates that $\mathrm{SO}_{2}$ emissions do not exceed $143 \mathrm{mg} / \mathrm{m}^{3}$ (it corresponds to the coefficient of binding of sulfur oxides by the mineral part of the fuel $\geq 75 \%$ ). The $\mathrm{SO}_{2}$ value decreases almost 1.5 times with a decrease in load from 297 to $205 \mathrm{t} / \mathrm{h}$. The value of $\alpha_{\mathrm{ss}}$ significantly affects $\mathrm{SO}_{2}$ emissions: with a decrease of $\alpha_{\mathrm{s}}, \mathrm{SO}_{2}$ emissions also decrease, other parameters remain constant.

\section{Technological mechanism of the sulfur dioxide transaction to calcium sulfate}

The presented dependencies can be explained by the following circumstances.

The rate of direct reaction (1) will be highest at the maximum temperature, that is, in the range of 1400-1500 $\mathrm{K}$. The longer the flue gases will be at the indicated temperatures, the higher the binding coefficient of sulfur oxides will be.

Flue gases move relatively slowly in the cooling chamber, where reaction (1) predominantly takes place. Then in convective gas ducts the gas velocity increases and the temperature decreases. Accordingly, the reaction rate decreases sharply (1). Consequently, the earlier the flue gases in the cooling chamber cool down to $1500 \mathrm{~K}$, the longer the reaction time (1) and the higher the binding coefficient of sulfur oxides will be .

It is known that with an increase in the boiler load, the temperatures of gases in the entire volume of the combustion chamber increase. This leads to a decrease in the $\mathrm{SO}_{2}$ binding coefficient. The same happens with an increase in $\alpha$ s in flue gases (an increase in the flow rate of blast air into the combustion chamber and a decrease in the residence time of the combustion products in the cooling chamber).

The influence of the vacuum systems number on the course of reaction (1) is ambiguous. On the one hand, when two vacuum systems are turned on, the rotational component of the gas movement, their turbolization and the reaction rate increase (1). On the other hand, an increase in the consumption of flue gases (with an increase in the number of dust systems) leads to an increase in their temperatures in the cooling chamber, which reduces the reaction time in the cooling chamber. So the $\mathrm{SO}_{2}$ emissions in experiment 10 (when 1 dust system is in operation) is noticeably lower than in experiments 11 and 2 (with the dust systems turned off). However, switching on two vacuum systems (eg 7.11) again increases $\mathrm{SO}_{2}$ emissions to the values of tests 11 and 2 .

Taking into account the above analysis, the following measures to reduce $\mathrm{SO}_{2}$ emissions can be proposed. Excess air should be supplied not to the combustion chamber, but to the cooling chamber so that the temperature of the gases after mixing with air is $1500 \mathrm{~K}$. This will increase the reaction time (1) and, accordingly, the $\mathrm{SO}_{2}$ binding coefficient. The fuel should be burned in the combustion chamber at $\alpha_{\text {c.ch }} \approx 1.015 \pm 0.05$. The proposed measure is a special case of staged 
compression technology and, of course, requires additional reconstruction of air ducts. As you know, staged combustion technologies are widely used to reduce $\mathrm{NO}_{x}$ emissions. In this case, they can reduce both $\mathrm{NO}_{\mathrm{x}}$ and $\mathrm{SO}_{2}$.
Another measure to reduce $\mathrm{SO}_{2}$ emissions can be recirculation of part of the ash from the ash collector to the cooling chamber. It will increase the area of its contact with $\mathrm{SO}_{2}$ and, accordingly, the formation of gypsum.

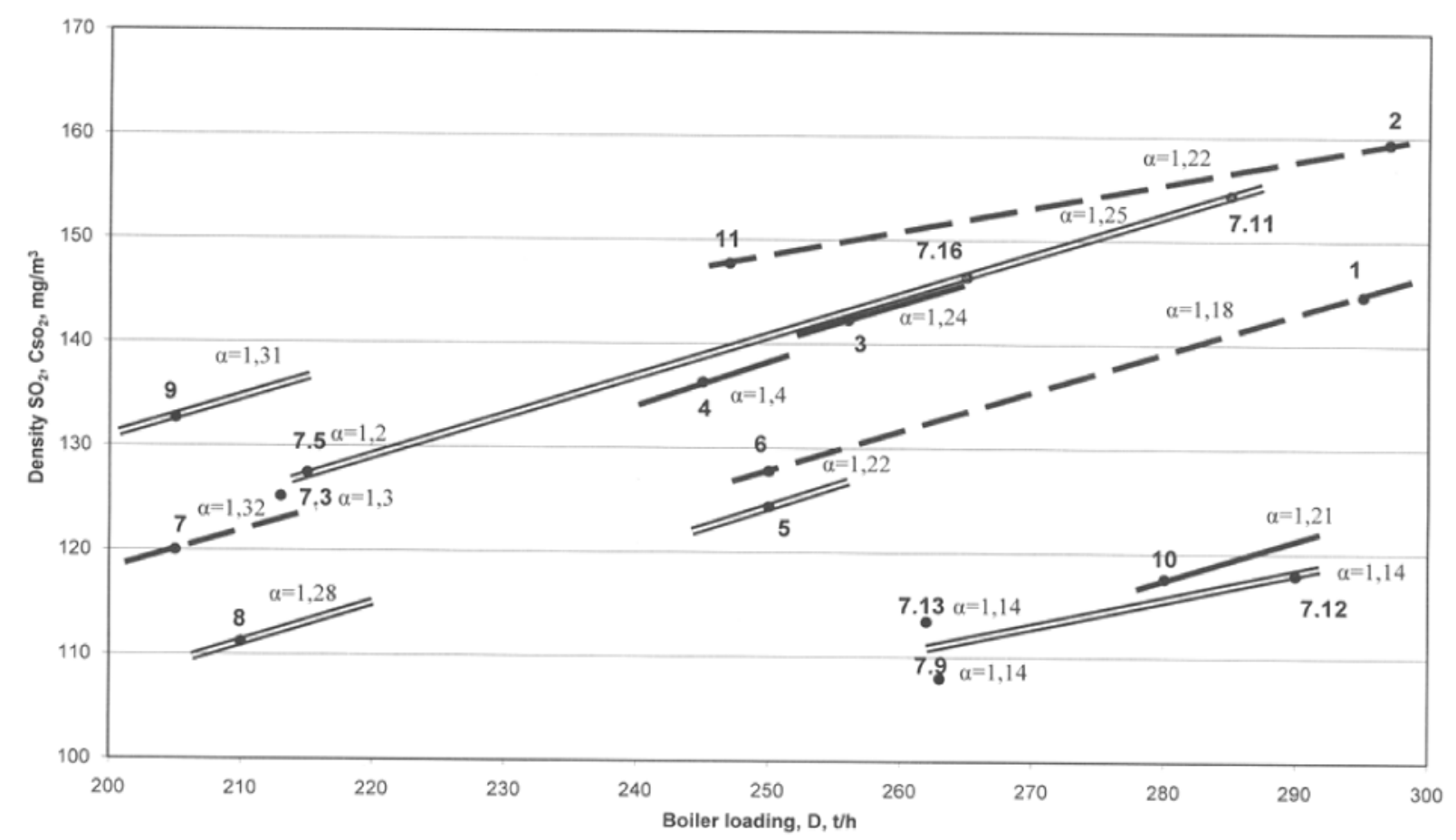

Fig. 3. Dependence of the density of sulfur dioxide on the boiler load, the number of working dust collecting systems and their combination, excess air (=== gases from two dust systems are discharged into the furnace; - gases from one dust system are discharged into the furnace; - . - - no drying agents are discharged into the furnace)

\section{Conclusions}

1) Based on the analysis of thermodynamic and industrial studies, a mechanism for the transition of sulfur dioxide to calcium sulfate during the combustion of Kansk-Achinsk coals in boilers with liquid slag removal is proposed;

2) It is shown that during the combustion of KAC in boilers with liquid slag removal, most of the fuel sulfur $(\geq 75 \%)$ is converted to calcium sulfate in the boiler cooling chamber in accordance with thermodynamic studies;

3) It was revealed that $\mathrm{SO}_{2}$ emissions increase with an increasing boiler load and air excess;

4) The number of operating dust collecting systems has a complex effect on $\mathrm{SO}_{2}$ emissions. On the one hand, an increase in this number leads to an increase in the consumption of flue gases and a decrease in the transition time of $\mathrm{SO}_{2}$ to $\mathrm{CaSO}_{4}$, on the other hand, the turbulization of combustion processes increases, and it accelerates the above transition;

5) Regime and constructive measures are proposed to reduce emissions of sulfur dioxide.

\section{References}

1. O.I. Budilov and A. S. Zavorin, Experience Gained from Measures on Improving the Performance Indicators of a Thermal Power Stations, Tomsk: Krasnoe Znamya (1994)

2. O.I. Budilov, N. V. Korenev, M. A. Rozhkov, Ya. I. Sokolova, Reducing emissions of harmful substances when burning Irsha-Borodino coal in the form of high-concentration dust, University news. Power Engineering №1, Pp. 61-63.(1991)

3. B. M. Kaganovich, A.V. Keiko, V. A. Shamansky, I. A. Shirkalin, M. S. Zarodnyuk, Technology of thermodynamic modeling. Reduction of motion models to rest models, Novosibirsk: Science (2010)

4. A.N. Gorban, B.M. Kaganovich, S.P. Filippov, A.V. Keiko, V.A. Shamansky, I.A. Shirkalin Termodinamic Equilibria and Extrema Analisis of Attainability Regions and Partial Equilibria, Springer (2006)

5. V.K. Elsukov, Complex researches of power sources efficiency in systems of centralized heat supply: autoadstract of dis. for the degree of doctor of technical Sciences, Irkutsk, (2012)

6. N.Yu. Kudryavtsev, V. V. Klimenko, V. B. Prokhorov, S. Yu. Snytin, Prospects for reducing emissions of sulfur oxides into the atmosphere 
when burning organic fuels, Heat and power engineering №2, Pp. 6-11.(1995)

7. A.A. Averin, N. Yu. Kudryavtsev, A.V. Usov, Formation of sulfur anhydride in the flue gases of steam boilers when burning sulfur fuel oil, Heat and power engineering no.1, Pp. 66-71. (1994)

8. S. Calvert, G. M. Inglund, Protection of the atmosphere from industrial pollution: Handbook: translation from English M.: Metallurgy,Vol. 1-760 s; Vol. 2-712 s.(1988)

9. Methodology for determining the gross emissions of harmful substances into the atmosphere from the thermal power plants boilers. MT 34-70-0130-83. Moscow: SPO \&quot;Soyuztekhenergo\&quot; (1984)

10. Methodology for determining the gross emissions of pollutants into the atmosphere from TPP boiler plants. RD 34.02.305-98-M.: AOOT VTI.(1998) 